\title{
New quality-control investigations on vaccines: micro- and nanocontamination
}

\begin{abstract}
Vaccines are being under investigation for the possible side effects they can cause. In order to supply new information, an electron-microscopy investigation method was applied to the study of vaccines, aimed at verifying the presence of solid contaminants by means of an Environmental Scanning Electron Microscope equipped with an X-ray microprobe. The results of this new investigation show the presence of micro- and nanosized particulate matter composed of inorganic elements in vaccines' samples which is not declared among the components and whose unduly presence is, for the time being, inexplicable. A considerable part of those particulate contaminants have already been verified in other matrices and reported in literature as non biodegradable and non biocompatible. The evidence collected is suggestive of some hypotheses correlated to diseases that are mentioned and briefly discussed.
\end{abstract}

Keywords: vaccine, disease, contamination, protein corona, biocompatibility, toxicity, nanoparticles, immunogenicity, foreign body, environment, industrial process, quality control
Volume 4 Issue I - 2017

\author{
Antonietta M Gatti, ${ }^{1,2}$ Stefano Montanari3 \\ 'National Council of Research of Italy, Institute for the Science \\ and Technology of Ceramics, Italy \\ ${ }^{2}$ International Clean Water Institute, USA \\ ${ }^{3}$ Nanodiagnostics srl, Italy
}

\begin{abstract}
Correspondence: Dr.Antonietta Gatti, National Council of Research of Italy, c/o Nanodiagnostics Via E. Fermi, I/L, 4I 057 San Vito (MO), Italy, Tel 059798778,
\end{abstract}

Email gatti@nanodiagnostics.it

Received: November 30, 2016 | Published: January 23, 2017

\section{Introduction}

Vaccines are one of the most notable inventions meant to protect people from infectious diseases. The practice of variolation is centuryold and is mentioned in Chinese and Indian documents dated around 1000 A.D. Over time, variolation has been replaced by vaccination, vaccines have been enhanced as to technology, and the vaccination practice is now standardized worldwide.

Side effects have always been reported but in the latest years it seems that they have increased in number and seriousness, particularly in children as the American Academy of pediatrics reports. ${ }^{1,2}$ For instance, the diphtheria-tetanus-pertussis (DTaP) vaccine was linked to cases of sudden infant death syndrome (SIDS) $;^{3}$ measles-mumpsrubella vaccine with autism;, 45 multiple immunizations with immune disorders; ${ }^{6}$ hepatitis B vaccines with multiple sclerosis, etc.

The notice of Tripedia DTaP by Sanofi Pasteur reports "Adverse events reported during post-approval use of Tripedia vaccine include idiopathic thrombocytopenic purpura, SIDS, anaphylactic reaction, cellulitis, autism, convulsion/grand mal convulsion, encephalopathia, hypotonia, neuropathy, somnolence and apnea". The epidemiological studies carried out did not show a clear evidence of those associations, even if in 2011 the National Academy of Medicine (formerly, IOM) admitted: "Vaccines are not free from side effects, or adverse effects".

Specific researches on components of the vaccines like adjuvants (in most instances, Aluminum salts) are already indicated as possible responsible of neurological symptoms ${ }^{8-10}$ and in some cases, in-vivo tests and epidemiological studies demonstrated a possible correlation with neurological diseases. ${ }^{10,11}$ Neurological damages induced in patients under hemodialysis treated with water containing Aluminum are reported in literature. ${ }^{12}$

Recently, with the worldwide-adopted vaccines against Human Papillomavirus (HPV), the debate was reawaken due to some adverse effects reported by some young subjects.

Specific studies communicated the existence of symptoms related to never-described-before syndromes developed after the vaccine was administered. For instance, Complex Regional Pain Syndrome (CRPS), Postural Orthostatic Tachycardia Syndrome (POTS), and Chronic Fatigue Syndrome (CFS). ${ }^{13}$ The side-effects that can arise within a relatively short time can be local or systemic.

Pain at the site of injection, swelling and uncontrollable movement of the hands (though this last symptom can also be considered systemic) are described. Among the systemic effects, fever, headache, irritability, epileptic seizures, temporary speech loss, lower limbs dysaesthesia and paresis, hot flashes, sleep disorders, hypersensitivity reactions, muscle pain, recurrent syncope, constant hunger, significant gait impairment, incapacity to maintain the orthostatic posture are reported. ${ }^{14}$

It is a matter of fact that every day millions of vaccine doses are administered and nothing notable happens, but it is also irrefutable that, regardless of the amount of side effects that are not recorded and the percentage of which remains in fact unknown, in a limited number cases something wrong occurs. No satisfactory explanation or, in many cases, no explanation at all has been given and it seems that those adverse effects happen on a random and stochastic basis.

Those situations induced us to verify the safety of vaccines from a point of view which was never adopted before: not a biological, but a physical approach. So, we developed a new analysis method based on the use of a Field Emission Gun Environmental Scanning Electron Microscope investigations to detect possible physical contamination in those products.

\section{Materials and methods}

44 types of vaccines coming from 2 countries (Italy and France) were analyzed. Table 1 groups them in terms of name, brand and purpose.

Some vaccines, in fact a minority, are meant to deal with a single bacterium or virus, while others are multi-valent. The list of vaccines we analyzed may contain repeated names, because we considered different batches and years of production of the same vaccine: the ones against influenza in particular. 
Table I List of vaccines analyzed, according to their purpose

\begin{tabular}{|c|c|c|c|c|}
\hline $\mathbf{N}$ & Name & $\begin{array}{l}\text { Brand Name, Country } \\
\text { of Distribution }\end{array}$ & Description & $\begin{array}{l}\text { Production Batch, } \\
\text { Expiry Date }\end{array}$ \\
\hline I & Vivotif Berna & Berna Biotech SA, Italy & Anti-Thyphoid Vaccine (Live), group Ty2 la & 3000336 [2004] \\
\hline 2 & Typhim Vi & Aventis Pasteur MSD, Italy & Anti-Salmonella typhi Vaccine & UI5I0-2 [2004] \\
\hline 3 & Typherix & GlaxoSmithKline S.p.a., Italy & Anti-Thypoid Vaccine (polysaccharide Vi) & ATYPB06IBB [2009] \\
\hline 4 & Anatetall & Chiron (now Novartis) Italy & Adsorbed anti-Tetanus Vaccine & $030106[2004]$ \\
\hline 5 & Anatetall & $\begin{array}{l}\text { Novartis Vaccines and } \\
\text { Diagnostics, Italy }\end{array}$ & Adsorbed anti-Tetanus Vaccine & 060510 [2009] \\
\hline 6 & Tetabulin & Baxter AG, Italy & Adsorbed anti-Tetanus Vaccine & VNG2G006A [2009] \\
\hline 7 & Dif-Tet-All & $\begin{array}{l}\text { Novartis Vaccines and } \\
\text { Diagnostics, Italy }\end{array}$ & Adsorbed anti-Tetanus and diphtheria Vaccine & 070501 [2009] \\
\hline 8 & Infanrix & GlaxoSmithKline S.p.a., Italy & Anti-Diphtheria, tetanus and pertussis vaccine & ACI4B07IAJ [2009] \\
\hline 9 & Infanrix hexa & $\begin{array}{l}\text { GlaxoSmithKline Biologicals } \\
\text { s, Italy }\end{array}$ & $\begin{array}{l}\text { Anti-diphtheria, tetanus, pertussis, hepatitis B, poliomyelitis } \\
\text { and disease caused by Haemophilus influenzae type b }\end{array}$ & A2ICC5I2A [ 20I7] \\
\hline 10 & Infanrix hexa & $\begin{array}{l}\text { GlaxoSmithKline Biologicals } \\
\text { s. a. France }\end{array}$ & $\begin{array}{l}\text { Anti-diphtheria, tetanus, pertussis, hepatitis B, poliomyelitis } \\
\text { and disease caused by Haemophilus influenzae type b }\end{array}$ & A2ICC42IA [ 20I7] \\
\hline 11 & M-M-R vaxPro & Sanofi Pasteur MSD, Italy & $\begin{array}{l}\text { M-M-R vaxPro (measles, mumps, and rubella) analyzed in } \\
\text { Cambridge }\end{array}$ & LOI2437 [ 2017] \\
\hline 12 & Repevax & Sanofi Pasteur MSD, France & Anti-diphtheria-tetanus-pertussis-polio-vaccine & L0362-I [2017] \\
\hline 13 & Repevax & $\begin{array}{l}\text { Sanofi Pasteur MSD SNC } \\
\text { France }\end{array}$ & Anti-diphtheria-tetanus-pertussis-polio-vaccine & L0033-I [2016] \\
\hline 14 & Priorix & GlaxoSmithKline S.p.a., Italy & Anti--measles-mumps, and rubella (MMR) vaccine & A69CB550A [2009] \\
\hline 15 & Morupar & $\begin{array}{l}\text { Chiron (now Novartis, ), } \\
\text { Italy }\end{array}$ & Anti-measles- mumps, and rubella (MMR) vaccine & 7601 [2004] \\
\hline 16 & Varilrix & GlaxoSmithKline S.p.a., Italy & Anti-Chicken pox vaccine (group OKA) & A70CA567A [2009] \\
\hline 17 & Stamaril Pasteur & Sanofi Pasteur MSD, Italy & anti-yellow fever vaccine & A5329-6 [2009] \\
\hline 18 & $\begin{array}{l}\text { Allergoid-Adsorbat } \\
\text { 6-Graser Starke B. }\end{array}$ & Allergopharma, Germany & Antiallergic vaccine & Ch-B.:30005999-B [2006] \\
\hline 19 & Engerix-B & GlaxoSmithKline S.p.a., Italy & Adsorbed anti-hepatitis B vaccine & AHBVB468BD [2009] \\
\hline 20 & Prenevar 13 & Pfizer, Italy & Antipneumococcal vaccine & G79324 [20I3] \\
\hline 21 & Prevenar 13 & Pfizer, France & Antipneumococcal vaccine & N27430 [ 2018] \\
\hline 22 & Mencevax Acwy & GlaxoSmithKline, Italy & $\begin{array}{l}\text { anti-Neisseria meningococcal group } \mathrm{A}, \mathrm{C}, \mathrm{WI} 35 \text { and } \mathrm{Y} \\
\text { vaccine }\end{array}$ & N402A47B I 2 [2004] \\
\hline 23 & Meningitec & Pfizer, Italy & (group C I0) (adsorbed on Al-Phosphate) & $\mathrm{H} 92709$ [20।5] \\
\hline 24 & Meningitec & Pfizer-Italy & $\begin{array}{l}\text { Anti-meningococcus (group C I0) vaccine (adsorbed on } \\
\text { Al-Phosphate) }\end{array}$ & $\mathrm{H} 20500[2014]$ \\
\hline 25 & Meningitec & Pfizer-Italy & $\begin{array}{l}\text { Anti-meningococcus vaccine sequestred by Procura della } \\
\text { Repubblica }\end{array}$ & G76673 [2014] \\
\hline 26 & Meningitec & Pfizer-Italy & $\begin{array}{l}\text { Anti-meningococcus vaccine sequestred by Procura della } \\
\text { Repubblica }\end{array}$ & H99459 [20I5] \\
\hline 27 & Meningitec & Pfizer-Italy & $\begin{array}{l}\text { Anti-meningococcus vaccine sequestred by Procura della } \\
\text { Repubblica }\end{array}$ & H52269 [2015] \\
\hline 28 & Menjugate & $\begin{array}{l}\text { Novartis Vaccines and } \\
\text { Diagnostics }\end{array}$ & Anti-meningococcus group $\mathrm{C}$ & YA0I63AB [2010] \\
\hline 29 & Menveo & $\begin{array}{l}\text { Novartis Vaccines and } \\
\text { Diagnostics }\end{array}$ & Antimeningococcus groups $\mathrm{A}, \mathrm{C}, \mathrm{WI} 35, \mathrm{Y}$ & AI5083 [20I7] \\
\hline 30 & Meningitec & $\begin{array}{l}\text { Wyeth Pharmaceutical - } \\
\text { France }\end{array}$ & Anti-meningococcus group $\mathrm{C}$ vaccine & $\mathrm{E} 83920[20 \mathrm{II}]$ \\
\hline 31 & InflexalV & Berna Biotech & Anti-flu vaccine $2008 / 2009$ & $300|463-0|$ [2009] \\
\hline 32 & Vaxigrip & Sanofi Pasteur MSD & Anti-flu vaccine $2008 / 2009$ & D9703-I [2009] \\
\hline 33 & Vaxigrip & Sanofi Pasteur & Anti-flu vaccine $2012 / 2013$ & J840I-I [20I3] \\
\hline 34 & Vaxigrip & Sanofi Pasteur, Italy & Anti-flu vaccine, with inactivated and split virus & M73।9-I [2016] \\
\hline 35 & Focetria & $\begin{array}{l}\text { Novartis Vaccines and } \\
\text { Diagnostics }\end{array}$ & Anti-pandemic flu HINI vaccine & $090240 \mathrm{I}[2010]$ \\
\hline 36 & Agrippal & Novartis & Anti-flu vaccine $2012 / 2013$ & I27002A [20I3] \\
\hline 37 & Agrippal & Novartis vaccines, Italy & Anti-flu vaccine with inactivated and split virus $2015 / 2016$ - & $152803[2016]$ \\
\hline 38 & Agrippal SI & $\begin{array}{l}\text { Novartis Vaccines and } \\
\text { Diagnostics }\end{array}$ & Anti-flu inactivated/superficial antigene v - 2014/20I5 & I47302A [20I5] \\
\hline 39 & Fluarix & GlaxoSmithKline - GSK & Anti-flu vaccine 2013 & AFLUA789AA [2014] \\
\hline 40 & Fluad & $\begin{array}{l}\text { Novartis Vaccines and } \\
\text { Diagnostics }\end{array}$ & Anti-flu inactivated/superficial antigene vaccine - 20I4/20I5 & $142502[20 \mid 5]$ \\
\hline
\end{tabular}


Table Continued..

\begin{tabular}{|c|c|c|c|c|}
\hline $\mathbf{N}$ & Name & $\begin{array}{l}\text { Brand Name, Country } \\
\text { of Distribution }\end{array}$ & Description & $\begin{array}{l}\text { Production Batch, } \\
\text { Expiry Date }\end{array}$ \\
\hline 41 & Gardasil & Sanofi Pasteur MSD, Italy & Anti-HPV types $6,11,16,18$ vaccine & NP0I250 [20I2] \\
\hline 42 & Gardasil & Sanofi Pasteur MSD, Italy & Anti-HPV (types $6,11,16,18$ ) vaccine & K023804 [2016] \\
\hline 43 & Cervarix & $\begin{array}{l}\text { GlaxoSmithKline Biological, } \\
\text { Italy }\end{array}$ & Anti-HPV (type I6,I8) & AHPVA238AX [2017] \\
\hline 44 & Feligen CRP & Virbac S.A. - Carros - Italy & $\begin{array}{l}\text { anti-panleucopenia, infectious rhinotracheitis and infections } \\
\text { by Calcivirus, veterinary Vaccine for cats }\end{array}$ & $3 R 4 R$ [20I3] \\
\hline
\end{tabular}

Table 2 List of the vaccines according to their manufacturers with the chemical composition of the debris identified in each sample. The elements most represented are reported

\begin{tabular}{|c|c|c|c|c|}
\hline $\mathbf{N}$ & Company & Name & Alluminum & Elements Identified \\
\hline I & Allergopharma - Germany & Allergoid & yes & $\mathrm{Al}$ \\
\hline 2 & Aventis Pasteur MSD Lyon - Francie & Typhim Vi & no & BrKP, PbSi, FeCr, PbClSiTi \\
\hline 3 & Baxter AG & Tetabulin & no & SiMg, Fe, SiTiAl, SBa, Zn \\
\hline 4 & Berna Biotech & Vivotif Berna & no & FeAl, ZrAlHf, SrAl, BiAlCl \\
\hline 5 & Berna Biotech & InflexalV & no & CuSnPbZn, Fe, CaSiAl, SiAl, NaPZn, ZnP,AISiTi \\
\hline 6 & Chiron & Anatetall & $\mathrm{Al}(\mathrm{OH}) 3$ & $\mathrm{FeAl}, \mathrm{SZnBaAl}$ \\
\hline 7 & Chiron & Morupar & no & l \\
\hline 8 & GlaxoSmithKline- Belgium & Mencevax ACWY & no & $\mathrm{FeCrNi}, \mathrm{ZrAl}, \mathrm{FeCrNiZrAISi}$ \\
\hline 9 & GlaxoSmithKline & Infanrix & $\mathrm{Al}(\mathrm{OH}) 3$ & $\mathrm{Al}, \mathrm{AlTi}, \mathrm{AlSi}$ \\
\hline 10 & GlaxoSmithKline Biologicals & Infanrix hexa & $\mathrm{Al}(\mathrm{OH}) 3$ & $\begin{array}{l}\mathrm{SBa}, \mathrm{FeCu}, \mathrm{SiAl}, \mathrm{FeSi}, \mathrm{CaMgSi}, \mathrm{AlCaSi}, \mathrm{Ti}, \mathrm{Au}, \mathrm{SCa} \\
\text { SiAlFeSnCuCrZn, CaAlSi }\end{array}$ \\
\hline 11 & GlaxoSmithKline Biologicals & Infanrix hexa & $\mathrm{Al}(\mathrm{OH}) 3$,AlPO4. 2H2O & $\mathrm{W}, \mathrm{FeCrNi}, \mathrm{Ti}$ \\
\hline 12 & GlaxoSmithKline & Typherix & no & Ti,TiW, AISiTiWCr, SBa,W, SiAl, AISiTi \\
\hline 13 & GlaxoSmithKline & Priorix & no & WCa, WFeCu, SiAl, SiMg, PbFe, Ti,WNiFe \\
\hline 14 & GlaxoSmithKline & Engerix-B & no & $\mathrm{Al}$ (precipitates) \\
\hline 15 & GlaxoSmithKline & Varilrix & no & FeZn, FeSi, AlSiFe, SiAlTiFe, MgSi, Ti, Zr, Bi \\
\hline 16 & GlaxoSmithKline & Fluarix & no & $\begin{array}{l}\text { AICu, Fe, AlBi, Si, SiZn, AICuFe, SiMg, SBa, AICuBi, FeCrNi, } \\
\text { SPZn }\end{array}$ \\
\hline 17 & GlaxoSmithKline Biologicals & Cervarix & $\mathrm{Al}(\mathrm{OH}) 3$ & AlSi,FeAl, SiMg, CaSiAl, CaZn, FeAISi, FeCr, CuSnPb \\
\hline 18 & Novartis Vaccines and Diagnostics & Anatetall & $\mathrm{Al}(\mathrm{OH}) 3$ & $\mathrm{Al}, \mathrm{FeCrNi}, \mathrm{AlCr}, \mathrm{AlFe}, \mathrm{BaS}, \mathrm{ZnAl}$ \\
\hline 19 & Novartis Vaccines and Diagnostics & Dif-Tet-All & $\mathrm{Al}(\mathrm{OH}) 3$ & $\mathrm{Fe}, \mathrm{SBa}, \mathrm{SiSBa}, \mathrm{AlZnCu}, \mathrm{AlZnFeCr}$ \\
\hline 20 & Novartis Vaccines and Diagnostics & Menjugate kit & $\mathrm{Al}(\mathrm{OH}) 3$ & SiAl,Ti,FeZn, Fe, Sb, SiAIFeTi,W, Zr \\
\hline 21 & Novartis Vaccines and Diagnostics & Focetria & no & $\begin{array}{l}\mathrm{Fe}, \mathrm{FeCrNiCu}, \mathrm{FeCrNi}, \mathrm{SiFeCrNi}, \mathrm{Cr}, \mathrm{SiAlFe}, \mathrm{AlSiTiFe}, \mathrm{AlSi} \\
\mathrm{SiMgFe}, \mathrm{Si}, \mathrm{FeZn}\end{array}$ \\
\hline 22 & Novartis & Agrippal SI & no & $\begin{array}{l}\mathrm{Ca}, \mathrm{Fe}, \mathrm{SBa}, \mathrm{SBaZn}, \mathrm{Cr}, \mathrm{Si}, \mathrm{Pb}, \mathrm{Bi}, \text { e FeSiAICr, SiAlSBaFe, CaAISi } \\
\mathrm{Zn}, \mathrm{CeFeTiNi}, \mathrm{FeCrNi}\end{array}$ \\
\hline 23 & Novartis Vaccines and Diagnostics & Agrippal SI & no & SiAlK, Si, SiMgFe, CaSiAl, SBaZn \\
\hline 24 & Novartis vaccines & Agrippal & no & $\mathrm{Cr}, \mathrm{Ca}, \mathrm{SiCaAl}, \mathrm{ZrSi}, \mathrm{SBa}, \mathrm{CuZn}, \mathrm{SCa}$ \\
\hline 25 & Novartis Vaccines and Diagnostics S & Fluad & no & CaSiAl, FeSiTi,SiMgAlFe, SBa \\
\hline 26 & Novartis Vaccines and Diagnostics & Menveo & no & CaSiAl, SiAlFe, FeCrNi, Fe, Al, SBa \\
\hline 27 & Pfizer & Prenevar 13 & no & $\mathrm{FeCr}$ \\
\hline 28 & Pfizer & Prevenar 13 & no & $\begin{array}{l}\text { W, CaAISi, Al, CaSiAlFe, FeS, FeCr, FeCrNi, Fe, , CaP, FeTiMn, } \\
\text { Ba, SiMgAlFe }\end{array}$ \\
\hline 29 & Pfizer & Meningitec - ctrl & no & $\mathrm{Cr}, \mathrm{Si}$ \\
\hline 30 & Pfizer & Meningitec - ctrl & no & $\mathrm{FeCrNi}, \mathrm{W}$ \\
\hline 31 & Pfizer & Meningitec & no & CaSiAl, CaSi, SiAlFeTi, FeCrNi,W, Fe, Pb \\
\hline 32 & Pfizer & Meningitec & no & $\mathrm{Cr}$ (precipitates), Ca, AISi \\
\hline 33 & Pfizer & Meningitec & no & W, SiCa, CaSi, Pb, FeCrNi, Cr \\
\hline 34 & Wyeth Pharmaceutical - UK & Meningitec & no & SiAIFe, SiAITi, SiMgFe, W, Fe, Zr, Pb, Ca, Zn, FeCrNi \\
\hline 35 & Sanofi Pasteur MSD-France & Vaxigrip & no & $\mathrm{Fe}, \mathrm{FeCrNi}$, SiAlFe, AISi, SiAIFeCr \\
\hline 36 & Sanofi Pasteur MSD & Stamaril Pasteur & no & CaSiAl, AlSi, Fe, SiMgFe, SiMgAlFe, CrSiFeCr, CrSiCuFe \\
\hline 37 & Sanofi Pasteur MSD & Gardasil & AIPO4. $2 \mathrm{H} 2 \mathrm{O}$ & $\mathrm{AlCuFe}, \mathrm{PbBi}, \mathrm{Pb}, \mathrm{Bi}, \mathrm{Fe}$ \\
\hline 38 & Sanifi Pasteur MSD & Gardasil & AIPO4. $2 \mathrm{H} 2 \mathrm{O}$ & CaAlSi, AlSi, SiMgFe, Al,Fe, AlCuFe, FeSiAl, BiBaS, Ti, TiAlSi \\
\hline 39 & Sanofi Pasteur & Vaxigrip & no & $\mathrm{Ca}, \mathrm{CrFe}, \mathrm{FeCrNi}, \mathrm{CaSZn}, \mathrm{CaSiAITiFe}, \mathrm{Ag}, \mathrm{Fe}$ \\
\hline 40 & Sanofi Pasteur & Vaxigrip & no & SiMgFe, CaSiAl, AlSiFe, AlSi,FeCr, FeZn, Fe \\
\hline 41 & Sanofi Pasteur MSD & Repevax & $\mathrm{AlPO} 4.2 \mathrm{H} 2 \mathrm{O}$ & $\mathrm{Bi}, \mathrm{Fe}, \mathrm{AlSiFe}, \mathrm{SiMg}, \mathrm{SBa}, \mathrm{Ca}$ \\
\hline 42 & Sanofi Pasteur MSD S & Repevax & AIPO4.2H2O & $\begin{array}{l}\text { Ti, Br, AuCuZn, Ca, SiZn, SiAuAgCu, SiMgFe, FeCrNi. } \\
\text { AlSiMgTiMnCrFe, SiFeCrNi, FeAl }\end{array}$ \\
\hline 43 & Sanofi Pasteur MSD & M-M-R vaxPro & no & $\begin{array}{l}\mathrm{Si}, \mathrm{SiFeCrNi}, \mathrm{FeCrNi}, \mathrm{FeNi} \text {, Fe, SCa, AlSiCa, CaAlSiFeV, SBa, Pt, } \\
\text { PtAgBiFeCr }\end{array}$ \\
\hline 44 & Virbac S.A. - Carros - France & Feligen CRP & no & $\mathrm{Ca}, \mathrm{SiAl}$ \\
\hline
\end{tabular}

Citation: Gatti AM, Montanari S. New quality-control investigations on vaccines: micro- and nanocontamination. Int J Vaccines Vaccin. 20 I 7;4(I):7-I4. DOI: I0.15406/ijvv.2017.04.00072 
Table 3 List of the debris' number identified in each vaccine as single particle, clusters and aggregates. Characterization is made by shape, size range and variability of the number of particles counted in each aggregate [in brackets]

\begin{tabular}{|c|c|c|c|c|c|c|}
\hline Name & Total Debris n. & $\begin{array}{l}\text { Size Range } \\
\text { in } \mathrm{mm}\end{array}$ & $\begin{array}{l}\text { Cluster } \\
\text { n. }\end{array}$ & $\begin{array}{l}\text { Size Range } \\
\text { in } \mathrm{mm}\end{array}$ & $\begin{array}{l}\text { Aggregate n.(Range } \\
\text { of Particles) }\end{array}$ & $\begin{array}{l}\text { Size } \\
\text { Range } \mathbf{m m}\end{array}$ \\
\hline Allergoid & $\mathrm{NaCl}$ precipitates & I & I & I & I & I \\
\hline Typhim Vi & 394 & $0,1-2,5$ & & & $3[9-350]$ & Feb-35 \\
\hline Tetabulin & 519 & $0,1-15$ & & & $3[100-180]$ & $25-60$ \\
\hline Vivotif Berna & 4 & $1,5-15$ & & & & \\
\hline InflexalV & 103 & $0,1-17$ & I & 20 & $3[35-45]$ & $25-O c t$ \\
\hline Anatetall & 2 & 3-Jan & & & & \\
\hline Morupar & I & & I & & l & \\
\hline Mencevax ACWY & 13 & $0,2-5$ & & & & \\
\hline Infanrix & 3 & 5-Jan & I & 25 & & \\
\hline Infanrix hexa & $|82|$ & $0,1-15$ & & & $15[1820]$ & $20-140$ \\
\hline Infanrix hexa & 162 & $0,3-7$ & 12 & 60 & $2[7$ debris $]$ & $3.5-44$ \\
\hline Typherix & 8 & $0,2-8$ & I & 15 & & \\
\hline Priorix & 641 & $0,05-30$ & I & 10 & $3[600]$ & $20-70$ \\
\hline Engerix-B & precipitates & & & l & & \\
\hline Varilrix & 2723 & $0,1-4$ & & & $36[120-2000]$ & $15-40$ \\
\hline Fluarix & 1317 & $0, I-40$ & & & $3[83]$ & 30-Jul \\
\hline Cervarix & 1569 & $0,2-3$ & 2 & I0-May & $4[1400]$ & 30-Aug \\
\hline Anatetall & 47 & $0,05-40$ & & & & \\
\hline Dif-Tet-All & III & $0,2-3$ & & & & \\
\hline Menjugate & 73 & $0,1-5$ & & & & \\
\hline Focetria & 35 & $0,7-10$ & & & & \\
\hline Agrippal SI & 430 & $0,2-6$ & 13 & $0.2-80$ & $5[410]$ & 20 \\
\hline Agrippal SI & 1029 & $0,1-12$ & & & $9[1025]$ & $35-80$ \\
\hline Agrippal & 480 & $0,1-6$ & & & II [ 460] & Feb-80 \\
\hline Fluad & 605 & $0,2-15$ & 4 & 25-Dec & $6[600]$ & 70 \\
\hline Menveo & 452 & $0,1-13$ & & & $4[430]$ & $30-110$ \\
\hline Prenevar 13 & precipitates +5 debris & 7-Jan & & & & \\
\hline Prevenar 13 & precipitates +81 debris & $0,2-50$ & 3 & May-40 & $\mathrm{I}[60]$ & 25 \\
\hline Meningitec & 3 & $20-O c t$ & & & & \\
\hline Meningitec & 24 & Aug-60 & & & & \\
\hline Meningitec & 673 & $0, I-20$ & I & 7 & $9[624]$ & $5-110$ \\
\hline Meningitec & precipitates +40 & $0,1-3,5$ & & & $2[40]$ & $25-70$ \\
\hline Meningitec & 177 & $0,2-10$ & & & $3[165]$ & $15-100$ \\
\hline Meningitec & $24 I$ & $0, I-I 5$ & 1 & 50 & $2[230]$ & 50 \\
\hline Vaxigrip & 86 & $0,1-7$ & & & $2[50]$ & $2-2,5$ \\
\hline Stamaril Pasteur & 152 & $0,1-7$ & 2 & 7-May & $3[145]$ & 20-Apr \\
\hline Gardasil & 304 & $0,05-3$ & & & $\mathrm{I}[300]$ & 15 \\
\hline Gardasil & 454 & $0.1-30$ & 2 & 20-Jul & $9[445]$ & May-60 \\
\hline Vaxigrip & 304 & $0, I-10$ & 1 & 13 & $2[300]$ & 35 \\
\hline Vaxigrip & 674 & $0,3-25$ & 2 & I2-Feb & $10[660]$ & $9-150$ \\
\hline Repevax & 137 & $0, I-20$ & & & $2[130]$ & $40-50$ \\
\hline Repevax & 214 & $0, I-10$ & & & $6[150]$ & 30-May \\
\hline M-M-R vaxPro & 93 & $0, I-15$ & & & $2[50]$ & $15-O c t$ \\
\hline Feligen CRP & 92 & $0,1-12$ & I & 12 & I (40 debris) & 25 \\
\hline
\end{tabular}

The study was aimed at verifying a possible physical contamination. To do that, we performed a new kind of investigation based on observations under a Field Emission Gun Environmental Electron Scanning Microscope (FEG-ESEM, Quanta 200, FEI, The Netherlands) equipped with the X-ray microprobe of an Energy Dispersive Spectroscope (EDS, EDAX, Mahwah, NJ, USA) to detect the possible presence of inorganic, particulate contaminants and identify their chemical composition.

A drop of about 20microliter of vaccine is released from the syringe on a 25-mm-diameter cellulose filter (Millipore, USA), inside a flow cabinet. The filter is then deposited on an Aluminum stub covered with an adhesive carbon disc. The sample is immediately put inside a clean box in order to avoid any contamination and the box is re-opened only for the sample to be inserted inside the FEG-ESEM chamber. We selected that particular type of microscope as it allows to analyse watery and oily samples in low vacuum (from 10 to $130 \mathrm{~Pa}$ ) at a high sensitivity.

When the water and saline the vaccine contains are evaporated, the biological/physical components emerge on the filter and it is then possible to observe them. This type of microscope (low-vacuum observations) prevents the possible sample contamination and the creation of artefacts. The observations are made with different sensors 
(SE: secondary-electron sensor and BSE: backscattered-electron sensor), and are performed at a pressure of 8.9 e-1 mbar, at energies ranging from 10 to $30 \mathrm{kV}$ to detect the particulate matter's size, morphology and its elemental composition. The method identifies clearly inorganic bodies with a higher atomic density (looking whiter) than the biological substrate. So, organic entities are visible and easy to distinguish from inorganic ones. The method cannot distinguish between proteins and organic adjuvants (e.g. squalene, glutamate, proteins, etc.) or viruses, bacteria, bacteria's DNA, endo-toxins and bacteria's waste, but their comparatively low atomic density allows us to identify these entities as organic matter. In some vaccines, the organic matter contains white-looking debris named aggregates, while a high concentration or inorganic debris is called a cluster.
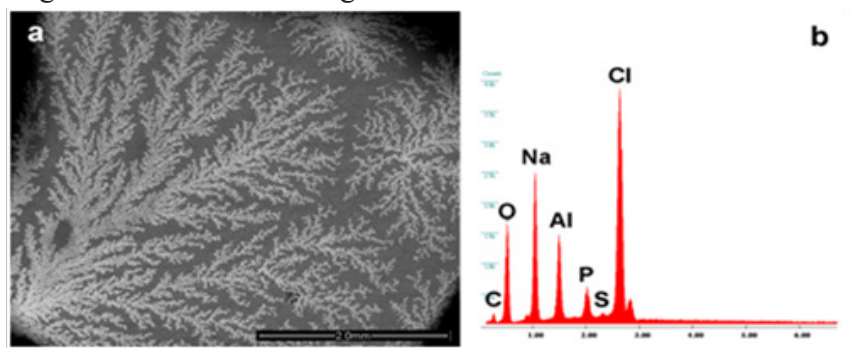

Figure I Crystals of saline solution and Aluminum Phosphate and corresponding EDS spectra.
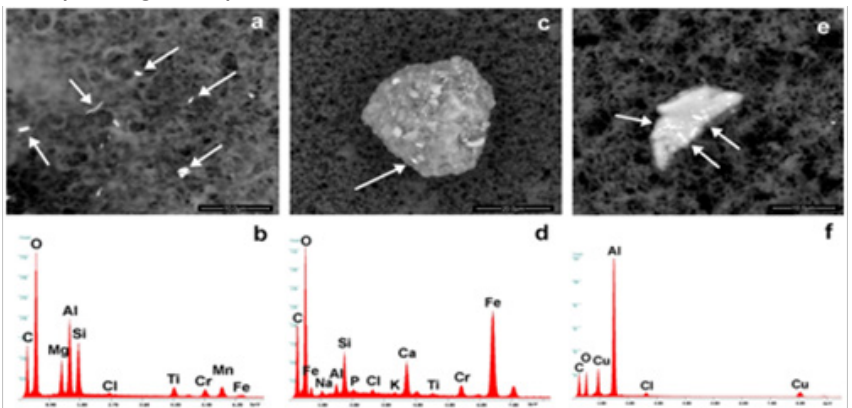

Figure 2 Images of single particles, cluster of micro- and nanoparticles $(<100 \mathrm{~nm})$ andaggregates with their EDS spectra. They are respectively composed of $(\mathrm{a}, \mathrm{b})$ Aluminum, Silicon, Magnesium, Titanium, Chromium, Manganese, Iron, (c,d) Iron, Silicon, Calcium Titanium, Chromium, (e,f) Aluminum, Copper. The arrows show the points where EDS spectra were taken.
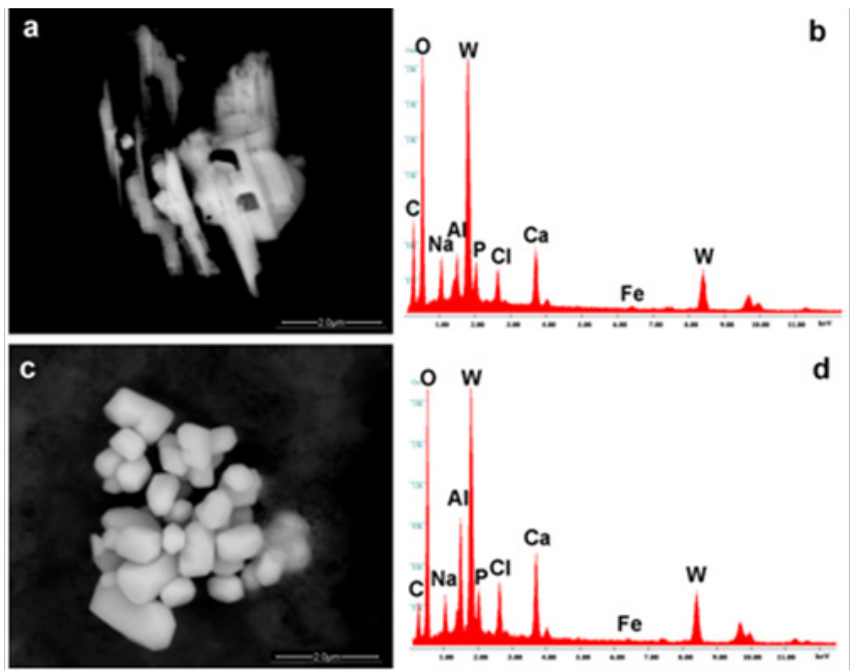

Figure 3 Images of Tungsten particles identified in drops of Prevenar and Infarix. They are composed respectively of Tungsten, Aluminum, Iron but in different concentrations. The arrows show the points where EDS spectra were taken.
Single inorganic particles or organic-inorganic aggregates are identified, evaluated and counted. The counting procedure is repeated three times by three different operators, with an error lower than $10 \%$. When a layer of salts (Sodium chloride or Aluminum) is detected, we record the situation but we do not do body count.

\section{Results}

The investigations verified the physical-chemical composition of the vaccines considered according to the inorganic component as declared by the Producer. In detail, we verified the presence of saline and Aluminum salts, but further presence of micro-, sub-micro- and nanosized, inorganic, foreign bodies (ranging from $100 \mathrm{~nm}$ to about ten microns) was identified in all cases, whose presence was not declared in the leaflets delivered in the package of the product (Table 2).Play Video

Figure 1a shows a layer of crystals of Sodium chloride $(\mathrm{NaCl})$ embedding salts of Aluminum phosphate $\left(\mathrm{AlPO}_{4}\right)$ in a drop of Gardasil (anti-HPV vaccine by Merck) as the EDS spectrum (Figure 1b) shows. Saline is the fluid base to any vaccine preparation and Aluminum salts or Aluminum hydroxide $\mathrm{Al}(\mathrm{OH}) 3$ are the adjuvants which are usually added.

Looking at the area outside these precipitates but inside the liquid drop, we identified other things: single particles, clusters of particles and aggregates (organic-inorganic composites) that are due to an interaction of the inorganic particulate matter with the organic part of the vaccine.

Figure 2a-2f shows the different typology of entities identified in the vaccines (Repevax, Prevenar and Gardasil); single particles, cluster of micro- and nanoparticles $(<100 \mathrm{~nm})$ and aggregates with their EDS spectra (Figure 2d-2f). The images (Figure 2a \& 2d) show debris of Aluminum, Silicon, Magnesium and Titanium; of Iron, Chromium, Silicon and Calcium particles (Figure $2 \mathrm{~b} \& 2 \mathrm{e}$ ) arranged in a cluster, and Aluminum -Copper debris (Figure 2c \& 2f) in an aggregate.

As can be seen, the particles are surrounded and embedded in a biological substrate. In all the samples analyzed, we identified particles containing: Lead (Typhym, Cervarix, Agrippal S1, Meningitec, Gardasil) or stainless steel (Mencevax, Infarix Hexa, Cervarix. Anatetall, Focetria, Agrippal S1, Menveo, Prevenar 13, Meningitec, Vaxigrip, Stamaril Pasteur, Repevax and MMRvaxPro).

Figure 3a-3d show particles of Tungsten identified in drops of Prevenar and Infarix (Aluminum, Tungsten, Calcium chloride).

Figure $4 \mathrm{a}-4 \mathrm{~d}$ present singular debris found in Repevax (Silicon, Gold, Silver) and Gardasil (Zirconium).

Some metallic particles made of Tungsten or stainless steel were also identified. Other particles containing Zirconium, Hafnium, Strontium and Aluminum (Vivotif, Meningetec); Tungsten, Nickel, Iron (Priorix, Meningetec); Antimony (Menjugate kit); Chromium (Meningetec); Gold or Gold, Zinc (Infarix Hexa, Repevax), or Platinum, Silver, Bismuth, Iron, Chromium (MMRvaxPro) or Lead,Bismuth (Gardasil) or Cerium (Agrippal S1) were also found. The only Tungsten appears in $8 / 44$ vaccines, while Chromium (alone or in alloy with Iron and Nickel) in 25/44. The investigations revealed that some particles are embedded in a biological substrate, probably proteins, endo-toxins and residues of bacteria. As soon as a particle comes in contact with proteic fluids, a nano-bio-interaction ${ }^{6}$ occurs and a "protein corona" is formed. ${ }^{7-10}$ The nano-bio-interaction generates a bigger-sized compound that is not biodegradable and can induce adverse effects, since it is not recognized as self by the body. 

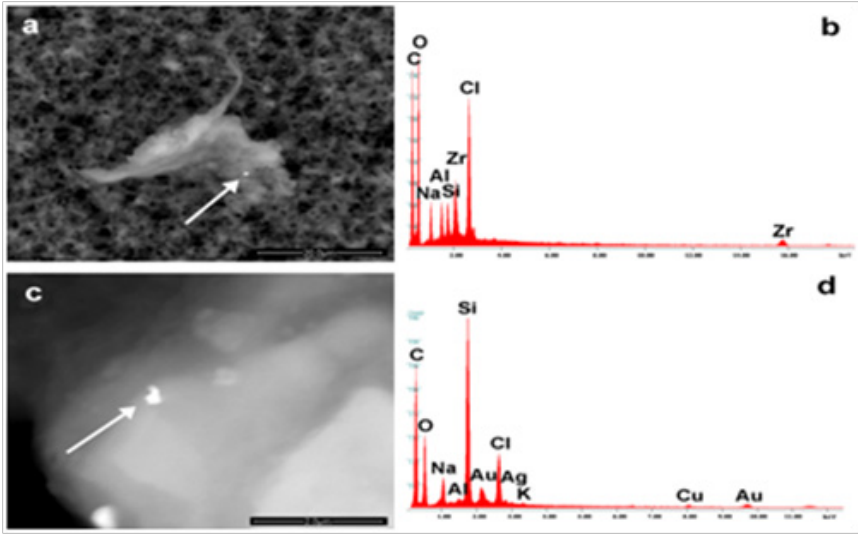

Figure 4 Images show examples of nano biointeraction. The aggregate $(a, b)$ identified in Gardasil contains nanoparticles of Chlorine, Silicon, Aluminum, Zirconium, while the debris found in Repevax contains Silicon, Gold, Silver (c,d).The arrows show the points where EDS spectra were taken.
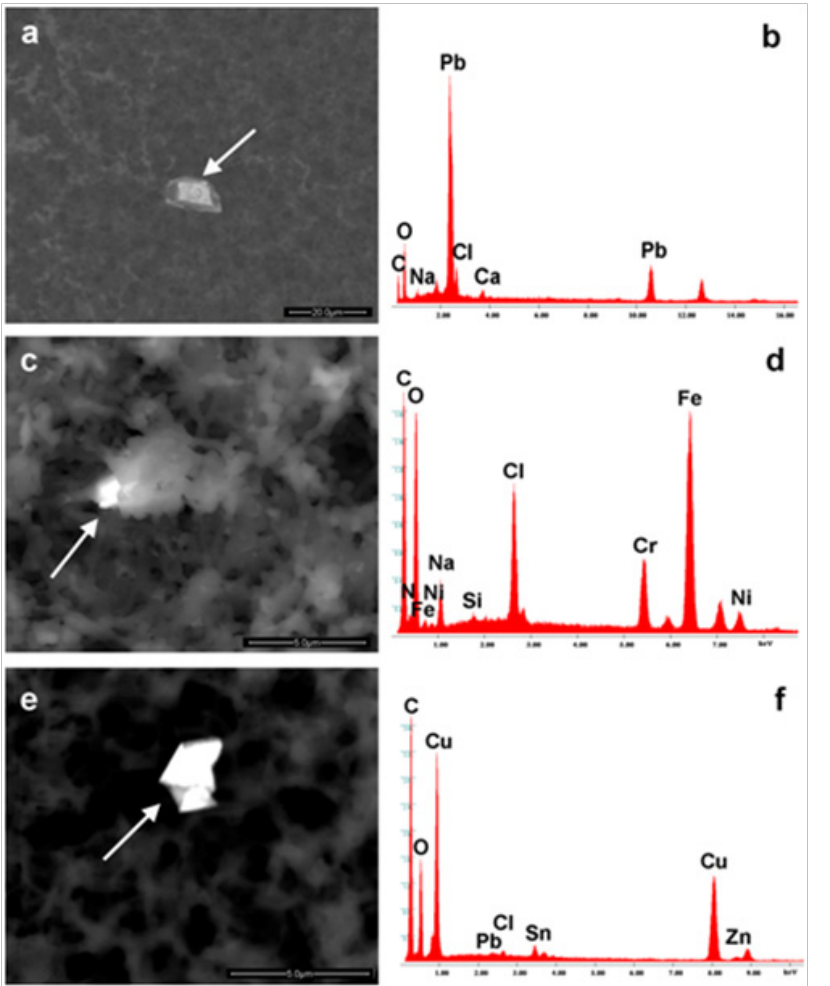

Figure 5 show particles surrounded by an organic compound. They are composed of Lead (a,b), Iron, Chromium, Nickel (stainless steel; c,d), Copper, Tin, Lead (e,f). The arrows show the points where EDS spectra were taken.

Figure 5a-5f show examples of these nano-bio-interactions. Aggregates can be seen (stable composite entities) containing particles of Lead in Meningitec, (Figure 5a \& 5b) of stainless steel (Iron, Chromium and Nickel, Figure 5c \& 5d) and of Copper, Zinc and Lead in Cervarix (Figure 5e \& 5f). Similar aggregates, though in different situations (patients suffering from leukemia or cryoglobulinemia), have already been described in literature.

The link between these two entities generates an unfolding of the proteins that can induce an autoimmune effect once those proteins are injected into humans.

Figure $6 \mathrm{a} \& 6 \mathrm{~b}$ show one of the foreign bodies identified in Agrippal. The particle is composed of Cerium, Iron, Titanium and
Nickel. (Figure 7a \& 7b) present an area of Repevax where the morphology of red cells - we cannot tell whether they are human or animal- is clearly visible.
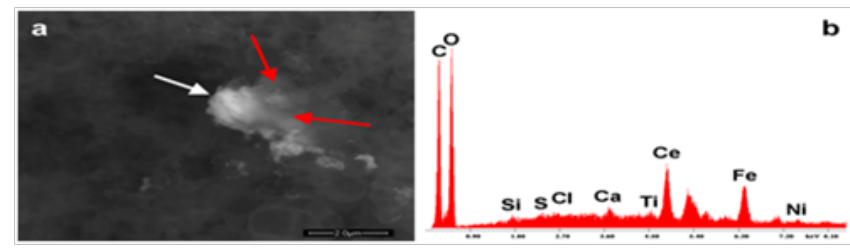

Figure $\mathbf{6}$ show an organic aggregate containing a debris made of Cerium, Iron, Nickel, Titanium. The red arrow indicates the organic layer (less atomically dense) that covers the Cerium particle.
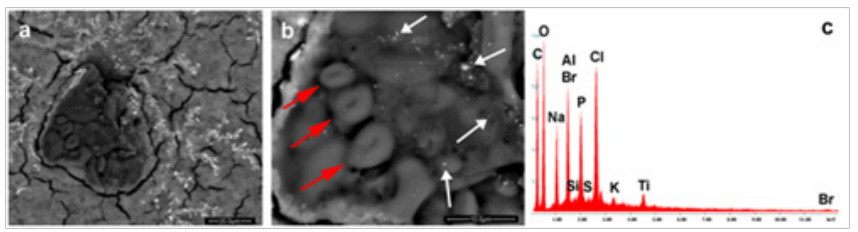

Figure 7 Image of an area in a Repevax drop where the morphology of red cells (red arrows) were identified. It is impossible to know whether they are human or animal origin. Among the debris of saline and Aluminum phosphate, there is the presence of debris (white arrows) composed of Aluminum, Bromine, Silicon, Potassium, Titanium.

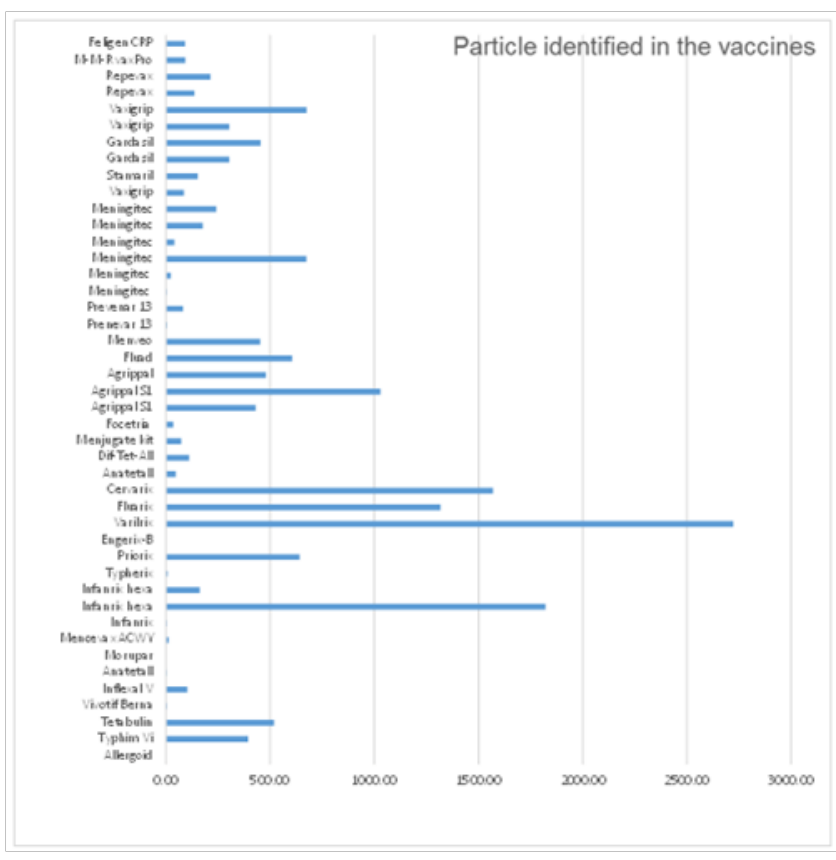

Figure 8 Graph of the debris' quantities identified in a 20 microl drop of every vaccine.

Table 3 summarizes the number and morphology of the debris identified, in term of single particles, clusters of particles or aggregates (organic-inorganic compounds), while Figure 8 shows the graph obtained calculating the total number of particles (particles plus clusters plus aggregates) identified for 20 microl of every vaccine.

Similar aggregates were already described by other scientists who identified them in the blood e.g. in leukemic patients ${ }^{15}$ and in subjects affected by cryoglobulinemia. ${ }^{16}$

Not all the vaccines analyzed contain the same contamination, though the same vaccine belonging to different batches and, in some cases, coming from different countries can contain a similar contamination (e.g. the vaccines by Glaxo Infarix, Typherix and 
Priorix contain Tungsten. Tungsten was also identified in Menjugate kit by Novartis, and Prevenar, Meningitec by Pfizer and Meningitec by Wyeth).

Feligen, the only veterinary vaccine tested, proved to be the only sample free from inorganic contamination, while Allergoid generates a layer of inorganic salts so thick that it does not allow to detect other particulate contaminants.

\section{Discussion}

The quantity of foreign bodies detected and, in some cases, their unusual chemical compositions baffled us. The inorganic particles identified are neither biocompatible nor biodegradable, that means that they are biopersistent and can induce effects that can become evident either immediately close to injection time or after a certain time from administration. It is important to remember that particles (crystals and not molecules) are bodies foreign to the organism and they behave as such. More in particular, their toxicity is in some respects different from that of the chemical elements composing them, adding to that toxicity which, in any case, is still there, that typical of foreign bodies. For that reason, they induce an inflammatory reaction.

After being injected, those microparticles, nanoparticles and aggregates can stay around the injection site forming swellings and granulomas. ${ }^{17}$ But they can also be carried by the blood circulation, escaping any attempt to guess what will be their final destination. We believe that in many cases they get distributed throughout the body without causing any visible reaction, but it is also likely that, in some circumstances, they reach some organ, none excluded and including the microbiota, in a fair quantity. As happens with all foreign bodies, particularly that small, they induce an inflammatory reaction that is chronic because most of those particles cannot be degraded. Furthermore, the protein-corona effect (due to a nanobio-interaction ${ }^{18}$ can produce organic/inorganic composite particles capable of stimulating the immune system in an undesirable way. ${ }^{19-22}$ It is impossible not to add that particles the size often observed in vaccines can enter cell nuclei and interact with the DNA. ${ }^{23}$

In some cases, e.g. as occurs with Iron and some Iron alloys, they can corrode and the corrosion products exert a toxicity affecting the tissues. $^{24-26}$

The detection of presence of Aluminum and $\mathrm{NaCl}$ salts is obvious as they are substances used by the Producers and declared as components, but other materials are not supposed to be in the vaccine or in any other injectable drug, at that, and, in any case, Aluminum has already been linked with neurological diseases..$^{27-29}$

Given the contaminations we observed in all samples of humanuse vaccines, adverse effects after the injection of those vaccines are possible and credible and have the character of randomness, since they depend on where the contaminants are carried by the blood circulation. It is only obvious that similar quantities of these foreign bodies can have a more serious impact on very small organisms like those of children. Their presence in the muscles, due an extravasation from the blood, could heavily impair the muscle functionality. ${ }^{30,31}$

We come across particles with chemical compositions, similar to those found in the vaccines we analyzed, when we study cases of environmental contamination caused by different pollution sources. In most circumstances, the combinations detected are very odd as they have no technical use, cannot be found in any material handbook and look like the result of the random formation occurring, for example, when waste is burnt. In any case, whatever their origin, they should not be present in any injectable medicament, let alone in vaccines, more in particular those meant for infants.

Other forms of so-far unknown contaminations have recently been observed and, in any case, vaccines contain components that could themselves be the cause of adverse effects. It is a well-known fact in toxicology that contaminants exert a mutual, synergic effect, and as the number of contaminants increases, the effects grow less and less predictable. The more so when some substances are unknown.

As a matter of fact, no exhaustive and reliable official data exist on the side-effects induced by vaccines. The episodic evidence reported by people allegedly damaged by vaccines is twofold: some say the damage occurred and became visible within a few hours from administration, and some maintain that it was a matter of some weeks. Though we have no indisputable evidence as to the reliability of those attestations, we can put forward a hypothesis to explain the different phenomena. In the former case, the pollutants contained in the drug have reached the brain and, depending on the anatomical site interested, have induced a reaction. If that is the case, the whole phenomenon is very rapid. In the latter circumstance, the pollutants reached the microbiota, thus interfering with the production of enzymes necessary to carry out neurological functions. ${ }^{32-35}$ That possibility takes time, as it involves the production of chemical compounds in a sufficient quantity, and an elapse of some weeks between injection and clinical evidence is reasonable. Of course, ours is no more than a hypothesis open to discussion and in need of proof, hoping that a chance of further investigation is allowed.

\section{Conclusion}

The analyses carried out show that in all samples checked vaccines contain non biocompatible and bio-persistent foreign bodies which are not declared by the Producers, against which the body reacts in any case. This new investigation represents a new quality control that can be adopted to assess the safety of a vaccine. Our hypothesis is that this contamination is unintentional, since it is probably due to polluted components or procedures of industrial processes (e.g. filtrations) used to produce vaccines, not investigated and not detected by the Producers. If our hypothesis is actually the case, a close inspection of the working places and the full knowledge of the whole procedure of vaccine preparation would probably allow to eliminate the problem.

A further purification of the vaccines could improve their quality and could probably decrease the number and seriousness of the adverse incidental effects.

\section{Acknowledgments}

The Authors are indebted to Dr. Federico Capitani, Dr. Laura Valentini and Ms. Lavinia Nitu for their technical assistance. The opinions and conclusions are not necessarily those of the Institution.

\section{Conflicts of interest}

Author declares there are no conflicts of interest.

\section{Funding}

None.

\section{References}

\section{Healthy Children.org}

2. US Dpt of health and human services. Report Update: Vaccine Side Effects, Adverse Reactions, Contraindications, and Precautions. $C D C$. 1996;45(RR-12):1-35. 
3. Ottaviani G, Lavezzi AM, Matturri L. Sudden infant death syndrome (SIDS) shortly after hexavalent vaccination: pathology in suspected SIDS? Virchows Arch. 2006;448(1):100-104.

4. Taylor B, Miller E, Farrington CP, et al. Autism and measles, mumps, and rubella vaccine: no epidemiological evidence for a causal association. Lancet 353(9169): 2026-2029.

5. Demicheli V, Rivetti A, Debalini MG, Di Pietrantonj C (2012) Vaccines for measles, mumps and rubella in children. Cochrane Database Syst Rev. 1999;15(2):CD004407.

6. Carola Bardage, Ingemar Persson, Åke Örtqvist, et al. Neurological and autoimmune disorders after vaccination against pandemic influenza A (H1N1) with a monovalent adjuvanted vaccine: population based cohort study in Stockholm, Sweden. BMJ. 2011;343:d5956.

7. Johann Liang R. Updating the Vaccine Injury Table following the 2011 IOM Report on Adverse Effects of vaccines. HRSA. 2012. p.1-27.

8. L Tomljenovic, CA Shaw. Aluminum Vaccine Adjuvants: Are they Safe? Current Medicinal Chemistry. 2011;18(17):2630-2637.

9. Shaw CA, Petrik MS. Aluminum hydroxide injections lead to motor deficits and motor neuron degeneration. J Inorg Biochem. 2009;103(11):1555-1562.

10. Authier FJ, Sauvat S, Christov C, et al. AlOH3-adjuvanted vaccineinduced macrophagic myofasciitis in rats is influenced by the genetic background. Neuromuscul Disord. 2006;16(5):347-352.

11. Exley C, Esiri MM. Severe cerebral congophilic angiopathy coincident with increased brain aluminium in a resident of Camelford, Cornwall, UK. J Neurol Neurosurg Psychiatry. 2006;77(7):877-879.

12. Wills MR, Savory J. Water content of aluminium, dialysis dementia, and osteomalacia. Environ Health Perspect. 1985;63:141-147.

13. Brinth L, Pors K, Theibel AC, et al. Suspected side effects to the quadrivalent human papilloma vaccine. Danish Medical $J$. 2015;62(4):1-12.

14. Palmieri B, Poddighe D, Vadalà $M$, et al. Severe somatoform and dysautonomic syndromes after HPV vaccination: case series and review of literature. Immunol Res. 2016.

15. Visani G, Manti A, Valentini L, et al. Environmental nanoparticles are significantly over-expressed in acute myeloid leukemia. Leuk Res. 2016;50:50-56.

16. Artoni E, Sighinolfi GL, Gatti AM, et al. Micro and nanoparticles as possible pathogenetic co-factors in mixed cryoglobulinemia. Occupational Medicine. 2016.

17. T Hansen, L Klimek, F Bittinger, et al. Mast cell reiches Aluminium granuloma Pathologe. 2008;29(4):311-313.

18. Gatti AM, Manti A, Valentini L, et al. Nano biointeraction of particulate matter in the blood circulation. Frontiers . 2016;30:3.

19. Tenzer S, Docter D, Rosfa S, et al. Nanoparticle size is a critical physicochemical determinant of the human blood plasma corona: a comprehensive quantitative proteomic analysis. ACS Nano. 2011;5(9):7155-167.
20. Radauer Preiml, Andosch A, Hawranek T, et al. Nanoparticleallergen interactions mediate human allergic responses: protein corona characterization and cellular responses. Fibre toxicology. 2015;13:3.

21. Cedervall T, Lynch I, Lindman S, et al. Understanding the nanoparticleprotein corona using methods to quantify exchange rates and affinities of proteins for nanoparticles. PNAS. 2016; 104 (7):2050-2055.

22. Lynch I, Cedervall T, Lundqvist $M$, et al. The nanoparticle-protein complex as a biological entity; a complex fluids and surface science challenge for the 21 st century. Advances in Colloid and Interface Science . 2007;134-135:167-174.

23. Gatti AM, Quaglino D, Sighinolfi GL. A Morphological Approach to Monitor the Nanoparticle-Cell Interaction. International Journal of Imaging and Robotics. 2009;2:2-21.

24. Urban RM, Jacobs JJ, Gilbert JL, et al. Migration of corrosion products from modular hip prostheses. Particle microanalysis and histopathological findings. The Journal of Bone and Joint Surgery. 1994;76(9):1345-1359.

25. Kirkpatrick CJ, Barth S, Gerdes T, et al. Pathomechanisms of impaired wound healing by metallic corrosion products. Mund Kiefer Gesichtschir . 2002;6(3):183-190.

26. Lee SH, Brennan FR, Jacobs JJ, et al. Human monocyte/macrophage response to cobalt-chromium corrosion products and titanium particles in patients with total joint replacements. J Orthop Res . 1997;15(1):40-49.

27. Shaw CA, Seneff S, Kette SD, et al. Aluminum-Induced Entropy in Biological Systems: Implications for Neurological Disease. Journal of Toxicology. 2014;2014:491316.

28. Shaw CA, Kette SD, Davidson RM, et al. Aluminum ${ }^{\mathrm{TM}_{\mathrm{S}}}$ Role in CNS-immune System Interactions leading to Neurological Disorders. Immunome Research. 2013;9:069.

29. Seneff S, Swanson N, Chen Li. Aluminum and Glyphosate Can Synergistically Induce Pineal Gland Pathology: Connection to Gut Dysbiosis and Neurological Disease. Agricultural Sciences . 2015;6(1):42-70.

30. Pegaz B, Debefve E, Ballini JP, et al. Effect of nanoparticle size on the extravasations and the photothrombic activity of meso(ptetracarboxyphenyl)porphyrin. $J$ Photochem Photobiol B. 2006;85(3):216-222.

31. Brinth LS, Pors K, Hoppe AG, et al. Is Chronic Fatigue Syndrome/ Myalgic Encephalomyelitis a Relevant Diagnosis in Patients with Suspected Side Effects to Human Papilloma Virus Vaccine? International Journal of Vaccines and Vaccination. 2015;1(1):1-5.

32. Moos WH, Faller DV, Harpp DN, et al. Microbiota and Neurological Disorders: A Gut Feeling. Biores Open Access. 2016;5(1):137-145.

33. Sekirov I, Russell SL, Caetano L, et al. Gut Microbiota in Health and Disease. Physiological Rev. 2010;90(3):859-904.

34. Umbrello G, Esposito S. Microbiota and neurologic diseases: potential effects of probiotics. J Transl Med. 2006;14(1):298.

35. Kinoshita T, Abe RT, Hineno A, et al. Peripheral sympathetic nerve dysfunction in adolescent Japanese girls following immunization with the human papillomavirus vaccine. Intern Med. 2014;53(19):2185-2200. 